\title{
Estratégias de inovação em APLs: viés para o desenvolvimento de produtos de moda
}

\author{
Yslene Rocha Kachba ${ }^{a *}$, Kazuo Hatakeyama ${ }^{\mathrm{b}}$ \\ a*yslener@utfpr.edu.br, UTFPR/UFSC, Brasil \\ `khatakeyama@unisinos.br, UNISINOS, Brasil
}

\begin{abstract}
Resumo
A gestão estratégica de inovação para o mercado de produtos de vestuário brasileiro tem encontrado determinadas barreiras, principalmente em relação ao desenvolvimento de produtos nas Pequenas e Médias Empresas (PMEs). Como estratégia para superar essa dificuldade, as PMEs têm-se organizado em Arranjos Produtivos Locais (APLs). Esta pesquisa apresenta um estudo multicaso de cinco APLs de confecção do estado do Paraná com organização igual ou maior a quatro anos de existência. A amostra total constituiu-se em 20 empresários agentes de governança, presidentes de sindicato e associações responsáveis pelos projetos de Pesquisa e Desenvolvimento (P\&D). A pesquisa analisou ações de P\&D apresentadas no planejamento estratégico dos arranjos a partir das estratégias de consolidação e roadmapping do Projeto Rotas Estratégicas para o Futuro da Indústria Paranaense. Encontrou-se dificuldades quanto às ações de $P \& D$ especialmente na criação da cultura de gestão de desenvolvimento de produto em conjunto com os empresários e fornecedores e as políticas públicas de incentivo a P\&D nas PMEs.
\end{abstract}

Palavras-chave

Estratégia de inovação. Gestão de desenvolvimento de produtos. Confecção. Arranjos produtivos locais.

\section{Introdução}

0 processo de globalização da economia que se iniciou nos anos 1990 alterou o mercado competitivo internacional. Esse fato teve como consequência nas indústrias brasileiras o imperativo de um pleno acolhimento das expectativas e necessidades dos clientes para sobreviver no ambiente de intensa competitividade.

No contexto empresarial, o desafio consiste na busca por maior participação no mercado e só consegue esse intuito quem estruturar a melhor estratégia de inovação. Mas qual estratégia pode ser utilizada quando a realidade é de PMEs com recursos escassos, tecnologia precária, carência de mão de obra especializada ou da pesquisa de novos produtos? A complexidade crescente do produto torna difícil para as PMEs trabalharem isoladamente, e conhecimento multidisciplinar é necessário para desenvolver novos produtos e promover a inovação (MALERBA, 1992; LAZOI et al., 2011). Esse conhecimento tem de acontecer em um processo coletivo e interativo entre os diversos atores, ou seja, organizações, centros de pesquisa, instituições, governo, entre outros.

Estratégias inovativas para P\&D podem ocorrer quando as PMEs adquirirem a cultura de passagem de um ambiente individualista de desenvolvimento de seus produtos para os esforços coletivos. Um processo de adaptação na direção de um ambiente cooperativo em formato de arranjos propicia a transferência de conhecimento em busca da inovação. Considerando essas organizações dispostas a terem sucesso de acordo com o ambiente, esse princípio se assemelha à rede de empresas, aglomerados ou Arranjos Produtivos Locais (APLs).

0 baixo nível de investimentos em $P \& D$ e marketing, caracterizado nas PMEs, reduz a capacidade de desenvolver radicalmente um produto, realizar inovações complexas e produtos personalizados. A natureza não estruturada de relações interfirmas (cooperação entre as empresas, instituições de ensino e pesquisa e órgãos governamentais) cria uma cultura que 
não apresenta apoio para processos eficazes e eficientes de codesign e codesenvolvimento (CARBONARA, 2005).

Neste artigo propõe-se constatar e analisar a Gestão de Desenvolvimento de Produto (GDP) levantando as estratégias de inovação utilizadas em 5 APLs de confecção do estado do Paraná por meio das propostas mapeadas pelo Projeto Rotas Estratégicas para o Futuro da Indústria Paranaense (PREPFIP). Essas estratégias de inovação são pautadas, principalmente, pelas fases de pré-desenvolvimento e pós-desenvolvimento sugeridas pelos autores Rozenfeld et al. (2006).

\section{Inovação estratégica em empresas organizadas em APLs}

A definição conotada por Porter (1998) para clusters ou APLs é de concentrações geográficas de empresas de determinados setores, atividades e organização correlatas. Normalmente se restringem às fronteiras políticas, o que não as impede de ultrapassar as fronteiras nacionais. Em APLs de sucesso existem redes de empresas inovadoras que contribuem com esforços inovadores e insumos. Em um APL onde a estratégia é a inovação, a rede de relacionamentos é a principal fonte de conhecimento (LAZOI et al., 2011). Para Souza e Arica (2006), o processo de entendimento da dinâmica competitiva de APLs é fundamental para a execução de estratégias competitivas precisas. Não há como analisar somente as estratégias competitivas, mas também a organização (formação gerencial e cultura empresarial) entre os agentes com o intuito de disseminar o conhecimento e a inovação por toda a rede, ou seja, a estratégia de conhecimento, pontuada na visão da inovação (CARBONARA, 2005).

Os conceitos, práticas e ações de desempenho do gerenciamento e a mensuração das atividades inovativas entre as empresas do APL devem estar vinculados a uma consolidada prática de cooperação. Amadurecimento e a troca de informações entre as empresas são fatores indispensáveis para um desenvolvimento eficaz e para a cultura contínua de inovação, parâmetros esses que contribuem para o desenvolvimento da coletividade e eficiência do APL. Assim, todas as ações de gerenciamento do APL devem estar vinculadas à eficiência da coletividade (CARPINETTI; GALDÁMEZ; GEROLAMO, 2008).

0 planejamento das ações nos APLs é chamado de plano de ação ou de desenvolvimento, o qual mostra o caminho para a execução de estratégias inovativas por meio de ações em conjunto de atores e agentes externos para a consolidação do APL. Entretanto, é necessário especificar que tipos de ações conjuntas ou iniciativas de cooperação os agentes locais desenvolveram e sua frequência - entre elas destacam-se: compra conjunta de insumos (central de compras); participação conjunta em feiras e exposições (nacionais e internacionais); estratégias compartilhadas de comercialização, tais como marca, propaganda, canais de distribuição, força de vendas, entre outras; compartilhamento de instalações, como unidades de manufatura e laboratórios de testes e certificação; realização de serviços conjuntos, como prospecção de mercado, provisão de informações; participação em consórcios de exportação; e estabelecimento em conjunto de escolas técnicas, centros de pesquisa para formação e qualificação da mão de obra (AMATO NETO, 2009).

Porém, para se conseguir uma contínua cultura de inovação, a rede de empresas tem a necessidade de preencher o espaço entre a inovação conseguida no APL e o mercado e trazer sustentabilidade. A ação para eliminar esta lacuna está no marketing coletivo, ou seja, o quanto a região e o mercado alvo conhecem o APL, seus produtos e suas atividades (O'DWYER; GILMORE; CARSON, 2009).

A coordenação extramercado e a presença de políticas públicas em APLs são essenciais na construção de vantagens competitivas localizadas. Os tipos de políticas públicas voltadas ao fomento de APLs geralmente são: incentivos fiscais; investimentos em infraestrutura urbana e construção de equipamentos públicos (estradas, aeroportos, concessão de terrenos, pavimentação, extensão de linhas de fornecimento de energia e redes de telefone etc.) (AMATO NETO, 2009; PEREIRA; CARVALHO, 2008). Logo, planejar e executar estratégias inovativas para ajudar as PMEs a desenvolver produtos competitivos no mercado onde atuam ou desejam atuar é o desafio da gestão dos APLs pesquisados.

\section{Gestão estratégica de inovação de produtos}

Para Fleury e Fleury (2003), as empresas necessitam de determinadas estratégias competitivas e de competências essenciais para sua internacionalização ou até mesmo para sua manutenção e conquista do mercado nacional. Entre elas está a necessidade de inovação de produtos e processos, estar continuamente investindo em criação de conceitos de produtos radicalmente novos para clientes e segmentos definidos. A função crítica para a inovação é representada por Pesquisa, Desenvolvimento e Engenharia (P\&D\&E). Para Cheng (2000), essa arquitetura organizacional é pontuada por Marketing, Pesquisa, Desenvolvimento e Engenharia de Manufatura.

As empresas com sucesso nessas atividades utilizam processos formais, com critérios definidos, com evidência para a preparação da equipe e para a qualidade na execução das ações. Diversos modelos de processo de desenvolvimento de produtos vêm sendo propostos na literatura. Clark e Wheelwright (1993) 
apresentaram o conceito de funil de desenvolvimento. Cooper (2008) contextualiza a ideia de estágios e pontos de decisão determinados para a condução de projetos de desenvolvimento e uma adaptação do modelo de stages-gates. Essa é uma forma mais ampla para englobar os desafios de conduzir estágios de base tecnológica, com grau de inovação de produtos e formas organizacionais para a sua formação.

Todavia, esses modelos devem ser pautados em ações planejadas e executadas considerando as especificações do ciclo de vida do produto (CVP). O CVP envolve toda a gestão do desenvolvimento do produto (GDP). A GDP, para Pich, Loch e Meyer (2002), pode acontecer por meio de aprendizagem de produtos anteriores, ou na adoção de uma estratégia seletista do melhor projeto.

Rozenfeld et al. (2006) sugerem a incorporação de mais duas fases nas etapas dos modelos de CVP, além do desenvolvimento em si, as macrofases de pré-desenvolvimento e pós-desenvolvimento. A primeira envolve as fases do projeto de desenvolvimento realizadas a partir das estratégias da empresa, delimitação das restrições de recursos, conhecimentos, informações sobre consumidores e levantamento de tendências tecnológicas e mercadológicas. A segunda macrofase é a atividade central pontuada no acompanhamento do ciclo de vida do produto, principalmente o conhecimento tácito gerado por ele nos colaboradores da empresa no decorrer dos seus processos.

A cadeia de inovação proposta por Hansen e Birkinshaw (2007) não atua somente com a fase de pós-desenvolvimento mas também com a geração de ideias para GDP, por todas as unidades da organização. Somente importar a inovação não resolve o problema da conquista de novos mercados, mas uma transformação inovativa de toda a cadeia, de colaboradores até fornecedores das empresas, sim. A conquista de novos mercados deve combinar as percepções e conhecimentos explícitos e tácitos de diferentes partes da mesma empresa. Embora não seja fácil de ser alcançada, essa conquista tem a finalidade de desenvolver novos produtos e até mesmo empresas. Descentralizar estruturas organizacionais e dispersões geográficas é difícil para pessoas acostumadas a atuar nas unidades. 0 modelo da cadeia de valor da inovação é dividido em três fases, geração de ideias, conversão e difusão.

Chesbrough e Crowter (2006) identificam o procedimento de open innovation. Essa é a terceirização do processo de desenvolvimento de produto, a compra de tecnologia. Essa estratégia coorporativa de inovação deve ser compatível com a natureza da oportunidade tecnológica para ser efetivamente explorada. 0 rigor de controle financeiro e o grau de decentralização das decisões de GDP devem ser adequados à magnitude de investimentos e grau de similaridade do mercado.
0 relatório da Associação Nacional de Pesquisa, Desenvolvimento e Engenharia das Empresas Inovadoras (ASSOCIAÇÃO..., 2004) cita que as empresas com maiores índices de desenvolvimento de inovações são aquelas de maior porte, independentemente da origem do capital. 0 processo de GDP é encontrado em empresas de base tecnológica (elétrica, química etc.), mas também encontra-se em menor escala nas empresas de bens de consumo (vestuário, alimentícia etc.).

0 desafio maior se consolida nas PMEs naexecução da gestão de inovação, principalmente em GDP em seus planos estratégicos. No plano microeconômico, mais precisamente na solução dos problemas estruturais que afetam as pequenas e médias empresas, deve ter início o processo de mudança em relação à inovação tecnológica. Igualmente, para que as políticas para as PMEs possam gerar melhores resultados, as ações devem ser levadas a efeito prioritariamente em aglomerações de empresas, como os arranjos produtivos locais (APLs), ou em grupos de empresas que constituam elos de uma mesma cadeia produtiva (ASSOCIAÇÃO..., 2004). Em geral, o que se tem visto como diagnóstico sobre as causas básicas das deficiências das PMEs em relação à inovação tecnológica é limitado à identificação dos gargalos tecnológicos. Para entender as estratégias de inovação para a GDP, pontuadas neste trabalho, é necessário entender as especificações do setor têxtil-vestuário.

\section{Desafios do setor têxtil vestuário e acessórios (confecção)}

0 setor têxtil brasileiro é reconhecido como uma das atividades econômicas com maior faturamento no Brasil, das que geram e giram recursos difíceis de serem ultrapassados, principalmente, no caso de produtos do vestuário como roupas femininas e masculinas (ASSOCIAÇÃO..., 2012). No Brasil, a cadeia produtiva têxtil gera 1.639 .932 empregos, participação de 17,1\% no emprego total da indústria nacional, ostenta produtividade anual média de 2.089.072 toneladas, correspondente a 5,7\% do faturamento total da indústria de transformação brasileira (INSTITUTO..., 2010). 0 setor de confecção de vestuário, especificamente, apresenta um número expressivo em relação à geração de empregos pelo fato de ter pouca utilização de tecnologia e o processo produtivo ser parcialmente manual.

A presente pesquisa se restringe somente à indústria de confecção, conceitualmente um conjunto de empresas que têm como seus fornecedores (fiação, malharias e tecelagens) empresas que transformam fibras naturais, artificiais ou sintéticas em tecidos. As confecções realizam o processo de costura e desenvolvimento final da peça que corresponde aos produtos: peças do vestuário pessoal para as modas 
feminina, masculina e infantil; produtos para o lar direcionados a cama, mesa e banho; decorativos, para a confecção de cortinas e toldos; e acessórios de uso individual, tais como bonés e luvas (ASSOCIAÇÃO..., 2012).

No Brasil, 27\% das indústrias de confecção estão localizadas na região sul, $11 \%$ estão no nordeste e a maioria, 58\%, na região Sudoeste. Os maiores estados produtores de artigos de confecção são Santa Catarina, São Paulo e Paraná. Observa-se que 90\% das indústrias de confecção são PMEs (ASSOCIAÇÃO..., 2012), assim surge a dificuldade de atingir novos mercados e mantê-los, por falta de planejamento, financiamento e o próprio conhecimento para desenvolvimento de novos produtos. Contudo, a globalização trouxe consigo a invasão do mercado brasileiro pelos produtos de países asiáticos, que atuam com a produção de itens de vestuário altamente padronizados e com preços baixos.

Na indústria de confecção, as maiores inovações ocorrem no design do produto e na organização da produção e marketing. As empresas que atuam no segmento de vestuário estão cada vez mais se dedicando à moda, tornando-se mais intensivas no processo de design. Os produtos da indústria do vestuário têm o seu mix de produção renovado a cada três meses, de acordo com as estações do ano. Esses contingentes de modificações de modelos exigem processos produtivos altamente flexíveis e otimizados, mesmo com os avanços no segmento de vestuário, como a utilização do Computer Aided Design (CAD) para a modelagem, desenho e corte e do Computer Aided Manufacturing (CAM) para a montagem e acabamento. Há ainda muitas operações manuais no processo produtivo e persiste a relação de um operador por máquina de costura. Cabe mencionar ainda que uma etapa que está em constante mudança é o acabamento, no qual ocorrem modificações tanto por meio de equipamentos como pela incorporação de agentes químicos aos produtos, dando a eles novos atributos quanto à característica e à aparência (LUPATINI, 2007).

0 setor de confecção paranaense é formado por empresas relativamente jovens ( $41 \%$ das empresas iniciaram no ano de 2000) em uma realidade de MPEs. As empresas desse segmento que possuem marcas próprias oferecem produtos padronizados. Com vendas voltadas para representantes, que seriam os catálogos ou varejistas, ou o produto é comercializado em grandes shoppings atacadistas, ou mesmo no próprio comércio local (OLIVEIRA; CÂMARA; BAPTISTA, 2007).

Encontra-se nesse setor alto índice de subcontratações nos processos de costura, bordado, lavanderia e estamparia. Muitas das empresas que prestam esses serviços não têm marcas próprias ou trabalham para grandes magazines, sendo a sua estratégia voltada para as exigências pautadas pela empresa para a qual ele é fornecedor nesse processo (SEN, 2008). A indústria de confecção brasileira apresenta a necessidade de desenvolver produtos personalizados, com alta tecnologia e baixos preços para vencer a concorrência externa.

\section{Projeto Rotas Estratégicas para o Futuro da Indústria Paranaense (PREPFIP): inovação para a competitividade}

O PREPFIP empregou a metodologia de roadmapping para mapear os setores com tendência de crescimento entre o período de 2005 até 2015 no estado do Paraná. 0 objetivo desse projeto foi mapear visões e estratégias para o futuro da indústria paranaense e os caminhos do mercado internacional por meio da inovação (SENAl, 2007).

0 roadmapping tem o intuito de levar a empresa ou o órgão em que vai ser aplicado a pensar no futuro e estruturar caminhos de crescimento e ações que permitam alcançar os objetivos planejados. 0 termo roadmapping é um neologismo inglês que para Phaal, Farrukh e Probert (2005) consiste no processo de planejamento tecnológico para identificar, selecionar e desenvolver alternativas tecnológicas que atendam um conjunto de necessidades de produção das empresas. Esse é um método que propicia desenvolver roadmap por meio de representações gráficas simplificadas que permitam comunicar e compartilhar de forma eficaz uma intenção estratégica com o intuito de mobilizar, alinhar e coordenar esforços das partes envolvidas para atender a um ou vários objetivos.

A realização do processo de roadmapping no estado do Paraná contou com a cooperação internacional da Fundação Observatório de Prospectiva Tecnológica Industrial (OPTI). A OPT1 foi responsável pela organização técnica e metodológica dos roadmappings, orientando cada etapa, em seis regiões diferentes do estado, conduzindo as discussões e atividades dos participantes durante os painéis com especialistas e empresários (SENAl, 2007). Para identificar ações estratégicas para o futuro do estado do Paraná foi realizado um mapeamento com especialistas regionais que atuam como empresários. Esses empresários definiram como futuro das indústrias paranaenses na fase 1: indústria agroalimentar; indústria de produtos de consumo, que inclui o setor de confecção; indústria da biotecnologia agrícola e florestal; indústria da biotecnologia animal; e indústria da microtecnologia. 0 setor de confecção caracterizado como futuro da indústria paranaense até o ano de 2015 foi selecionado para a análise do desempenho atual. A estrutura do processo de roadmappings é apresentada na Figura 1.

A partir dos roadmappings, com os especialistas e empresários dos setores formularam-se cinco visões 
para o futuro desejado da indústria paranaense de produtos de consumo. Mapeou-se por meio da metodologia, estratégias e ações para vencer os desafios encontrados para a realização de cada visão, como mostra o Quadro 1.

As visões inovativas pontuadas pelos pesquisadores do PREPFIP foram pautadas em relação ao processo de inovação das empresas paranaenses. Desde Schumpeter (1934), os autores vêm estudando a importância do processo de inovação de empresas. Eles também afirmam que a organização em APL é estruturada para conseguir sua consolidação e, para isso, precisa de uma cultura de inovação em parceria com instituições de pesquisa e ensino, governamentais e financeiras (NIU; MILES; LEE, 2008; CASSIOLATO; LASTRES; MACIEL, 2003; CARPINETTI; GALDÁMEZ; GEROLAMO, 2008). As visões inovativas voltadas para organização, marketing, produtos, processos e novos materiais são para consolidar ações para o crescimento das PMEs e a ruptura da sua cultura individualista.

A implementação das tecnologias da informação e comunicação (TICs) é necessária para toda a evolução da produção e gestão das PMEs. Nas indústrias de confecção as ferramentas de software mais utilizadas são sistemas de gestão de otimização de corte e encaixe de tecido. As parcerias são alicerces para todo tipo de APL e as ações de políticas públicas são consequência de eficientes parcerias com instituições governamentais (SENAl, 2007). A gestão de marcas é pontuada como a necessidade da identificação, ou seja, de as pessoas reconhecerem os produtos manufaturados no APL pela marca ou selo do arranjo. $\mathrm{Na}$ atualidade, a conquista de mercados nacionais e internacionais é uma necessidade de sobrevivência das indústrias de confecção.

Pesquisa e desenvolvimento, tecnologia e inovação são parâmetros necessários para a versatilidade da transformação rápida de modelos de produtos que a indústria de confecção exige (OLIVEIRA; CÂMARA; BAPTISTA, 2007; PEREIRA et al., 2011). Cria-se uma nova coleção a cada ciclo de mudança de estação do ano, o que exige materiais de qualidade superior, principalmente, nos tecidos. Tecnologias para desenvolver, produzir e vender os produtos em três meses e todos estes fatores voltados para uma cultura de inovação que o mercado atual estabelece. A qualidade dos produtos no mercado de confecção se constitui em proporcionar maior conforto, durabilidade, flexibilidade e beleza para o usuário da peça a ser produzida. 0 maior desafio está no equilíbrio entre o nível de qualidade e os recursos disponíveis para a compra de materiais para a sua produção. 0 foco no resultado no APL e o design estratégico têm a vertente para a governança, na qual o plano de ação deve ter uma visão correta do futuro e das necessidades de firmar parcerias na elaboração das ações.

Quadro 1. Roadmapping de empresas de produtos de consumo paranaenses.

\begin{tabular}{|c|c|}
\hline Visão & Estratégia \\
\hline $\begin{array}{l}\text { Inovação } \\
\text { organizacional: } \\
\text { empresas em rede }\end{array}$ & $\begin{array}{l}\text { Formação gerencial e cultura empresarial } \\
\text { Implementação de TICs } \\
\text { Parcerias } \\
\text { Políticas públicas }\end{array}$ \\
\hline $\begin{array}{l}\text { Inovação em marketing: } \\
\text { imagem de marca forte }\end{array}$ & $\begin{array}{l}\text { Propriedade industrial } \\
\text { Cultura empresarial } \\
\text { Gestão de marca } \\
\text { Mercado nacional e internacional }\end{array}$ \\
\hline $\begin{array}{l}\text { Inovação em produto: } \\
\text { design e tecnologia }\end{array}$ & $\begin{array}{l}\text { P\&D, tecnologia e inovação } \\
\text { Políticas públicas } \\
\text { Qualidade e sustentabilidade } \\
\text { Foco no resultado }\end{array}$ \\
\hline $\begin{array}{l}\text { Novos materiais: } \\
\text { valor agregado e } \\
\text { sustentabilidade }\end{array}$ & $\begin{array}{l}\text { Design estratégico } \\
\text { P\&D e inovação } \\
\text { Acesso à tecnologia } \\
\text { Propriedade industrial }\end{array}$ \\
\hline
\end{tabular}

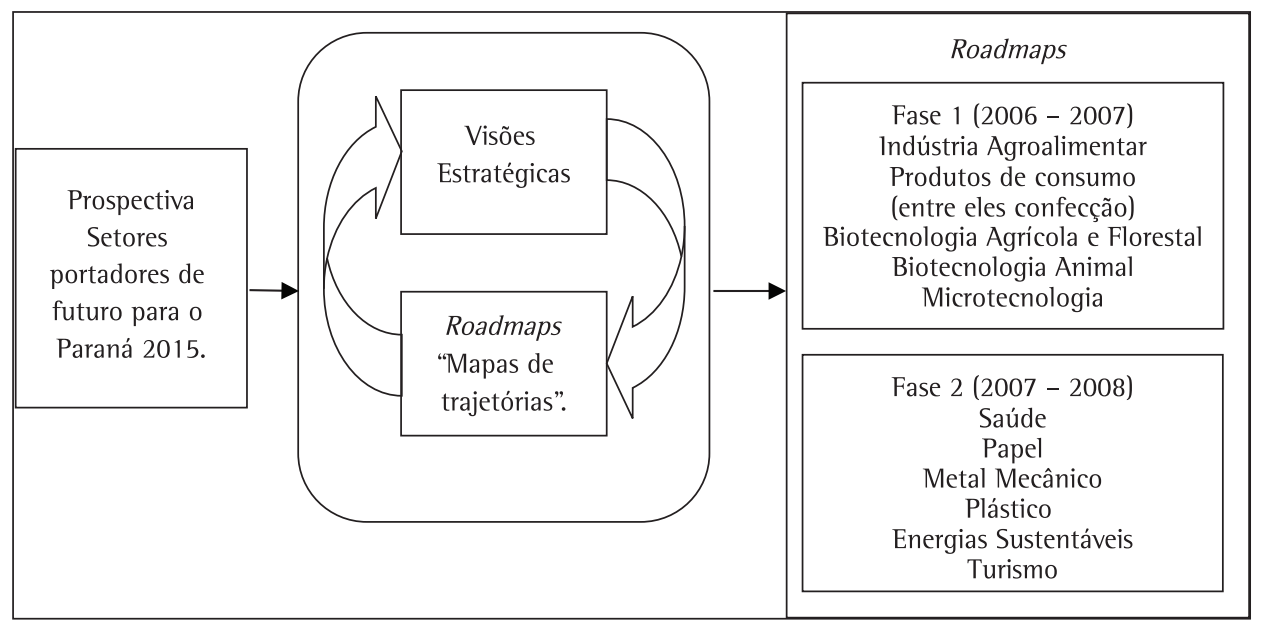

Figura 1. Modelo de processo de geração dos roadmappings da indústria do Paraná. Fonte: SENAl (2007). 
A escolha da problemática desta pesquisa consolidou-se em virtude do setor de confecção ser uma das atividades caracterizadas para o futuro da indústria paranaense até o ano de 2015. Assim, formularam-se cinco visões para o futuro desejado da indústria paranaense de produtos de consumo. Mapearam-se por meio da metodologia estratégias e ações para vencer os desafios encontrados para a realização de cada visão. Os desafios que se apresentam são o de mapear os planos de ação dos APLs de confecção do estado do Paraná, de acordo com as visões e estratégias do PREPFIP, e o de identificar as ações realizadas para a sua consolidação na GDP.

\section{Metodologia}

A presente pesquisa se contextualiza como estudo multicaso, assim caracterizado por Yin (2001): maior foco na compreensão e na comparação quantitativa dos fenômenos; proporciona maior abrangência dos resultados, não se limitando às informações de uma só organização; o método empregado é dedutivo e exploratório, com abordagem predominantemente qualitativa em relação a descobrir ações estratégicas dos atores da governança dos APL em relação à disseminação de conhecimento inovativo para a GDP.

De acordo com esse conceito, a população desta pesquisa restringiu-se a agentes empresários da governança dos APLs e presidência de associações ou sindicatos de confecção do estado do Paraná com organização maior ou igual a quatro anos de existência, de acordo com a Federação das Indústrias do Estado do Paraná (FIEP). Os procedimentos técnicos foram realizados por meio da pesquisa documental nos planos de ação dos APLs. Questionários foram aplicados aos agentes de governança e presidência de associações e sindicatos de confecção do estado do Paraná e observação sistemática nas empresas, projetos e capacitação dos APLs foram realizadas. A amostra caracterizou-se com os seguintes agentes:

a) Malhas de Imbituva: entrevista com 3 líderes de governança do APL e o presidente da associação, observação em reuniões, missões internacionais, visitas a empresas e treinamento com 22 empresários;

b) Moda Masculina região Sudoeste: entrevista com 2 líderes e administradora da governança e presidente do sindicato, visita a projetos de formação e empresas;

c) Roupa Bebê Terra Roxa: entrevista com 4 líderes da governança, visita às empresas, participação na formação de planejamento estratégico do APL;

d) Vestuário Maringá: entrevista com 2 líderes e administradora da governança e o presidente do sindicato, visita a projetos, reuniões em empresas, treinamento de empresários e representantes; e

e) Bonés Apucarana: entrevista com 3 líderes da governança e o presidente do sindicato, visita a reuniões e empresas.
No universo de APLs de confecção do estado do Paraná, somente um não participou da pesquisa por motivos de reestruturação da governança. Assim, as pessoas responsáveis pelos projetos de $\mathrm{P} \& \mathrm{D}$ da antiga gestão se recusaram a participar da pesquisa. Um dos questionários não foi respondido em sua totalidade, o que resultou em sua retirada da pesquisa.

A pesquisa foi realizada em 16 meses, nos anos de 2008 e 2009, com o auxílio de instrumentos de imagem e som. Os questionários, respondidos presencialmente, continham 76 questões: 7 sobre a qualificação individual dos gerentes, 25 sobre inovação organizacional, 16 sobre inovação em marketing, 17 sobre inovação de produtos e processos e 11 sobre desenvolvimento de novas matérias-primas para 0 setor de confecção. As observações sistemáticas nos APLs de confecção tiveram como objetivo constatar a existência de centros de treinamentos e design no APL, parcerias com instituições nacionais e internacionais, realização de projetos de pesquisa voltados para a área de desenvolvimento de produto.

\section{Pesquisa de campo}

Nos cinco APLs de confecção paranaense pesquisados atuam 1.942 empresas médias, pequenas e grandes. Entre os APLs, todos os cinco apresentam estrutura de treinamento: três em centros de treinamento de mão de obra e somente dois em parceria com universidades. Entre os agentes de governança, presidentes de sindicatos e associações que responderam à pesquisa, 85\% possuem diplomas de nível superior e 15\%, de nível médio. Todos são empresários do setor de confecção, com as empresas atuando há mais de quatro anos na organização de APL.

Os resultados serão apresentados separadamente, de acordo com a estratégia de inovação a ser pesquisada em relação ao desenvolvimento de produto. Alguns resultados apresentam citações diretas de agentes de governança dos APLs, presidentes de associações e sindicatos, pois eles apresentam e certificam as realidades encontradas nos dados e a dificuldade de formação de parceria com empresas para ações inovativas no processo de desenvolvimento de produtos.

\subsection{Inovações organizacionais: redes de empresas}

Essa categoria de inovação consiste na fase exposta por Rozenfeld et al. (2006) como de pré-desenvolvimento, ou seja, descobrir de que modo o assessoramento das ações inovativas dos APLs de confecção poderia contribuir para o desenvolvimento da organização das PMEs de confecção para a GDP (HANSEN; BIRKINSHAW, 2007; CARBONARA, 2005).

Demonstra a necessidade da geração de ideias na organização tornando-se uma gestão de inovação de 
cadeia de valor, o que seria uma transformação cultural das empresas. Essas empresas foram pautadas nas estratégias dos arranjos por meio de transferência de conhecimentos tácitos e explícitos para tendências organizacionais, tecnológicas e de mercado. Também foram pautadas com a realização de acordos de cooperação internacionais, principalmente com clusters de vestuário do norte da ltália, como apresenta a Tabela 1.

A formação com parceiros nas estratégias gerenciais é o fator no qual se concentra a maior quantidade de ações nos planos de ação dos APLs. Contudo, elas se restringem ao treinamento de colaboradores para melhoria da performance, geralmente nos setores de produção e vendas. A teoria de open innovation exercida com parcerias de instituições de pesquisa para a P\&D do APLs geralmente não acontece. Nessa fase, os arranjos só concretizavam os treinamentos para conhecimento de GDP, como apresenta a Figura 2.

As PMEs de confecção paranaense têm consciência e executam estratégias em conjunto para a evolução da organização de GDP. Entre as inovações propostas nesta pesquisa, a inovação organizacional teve índices mais altos positivamente, $71 \%$ das opções que apresentavam ações voltadas para inovação organizacional foram entre grande e plausivel. Contudo, no subitem de implementação de Tecnologias de Informação e Comunicação (TICs) nas empresas, apresentaram-se os menores índices positivos de existência. Isso demonstra, ainda, dificuldade de comunicação nas empresas e, como consequência, para a geração e difusão de ideias para a GDP.

Para confirmar essa realidade, a afirmação de um dos agentes de governança dos APLs: "O trabalho em conjunto evoluiu muito nas empresas da região, antes de sermos empresários éramos trabalhadores rurais, não tínhamos conhecimento de tendências de mercado e desenvolvimento de produtos".

\subsection{Inovações em marketing: imagem da marca forte}

Nessa etapa de inovação também se trabalha com a macrofase de pré-desenvolvimento de Rozenfeld et al. (2006), como o estudo de marketing da marca do
APL em conjunto com a marca de cada uma das empresas, conforme ilustrado na Tabela 2.

A divulgação dos produtos em mercados nacionais e internacionais acontece por meio da cooperação das ações em um dos cinco APLs pesquisados. Também se observou a criação da cultura de registro de propriedade industrial e financiamento para registro internacional das marcas, porque o grau de consolidação de APLs tem uma de suas variáveis marcada pelo nível de exportação do APL. A mensuração das estratégias de inovação em marketing é apresentada na Figura 3.

Essa estratégia de inovação apresenta menores índices positivos que a inovação organizacional. A somatória das ações grande e plausível pontua somente $37 \%$ e nenhuma ação voltada para o marketing, em 29\%. 0 que impressiona nessa realidade é que a variável que apresentou maior valor de nenhuma ocorrência foi a de gestão de marca, principalmente, em relação à marca em conjunto do APL. Contrapondo essa realidade encontraram-se altos índices de ações voltadas para o registro de marcas e busca de novos mercados, fator que demonstra o interesse dos empresários em ações voltadas para a busca de inovações que não prejudiquem a cultura de não desenvolver produtos em conjunto.

\subsection{Inovação de produtos e processos: design e tecnologia}

Essa inovação mostra as ações em conjunto dos APLs em relação ao desenvolvimento de produtos e processos propriamente ditos. A produção em massa do setor do vestuário tende a se transformar em

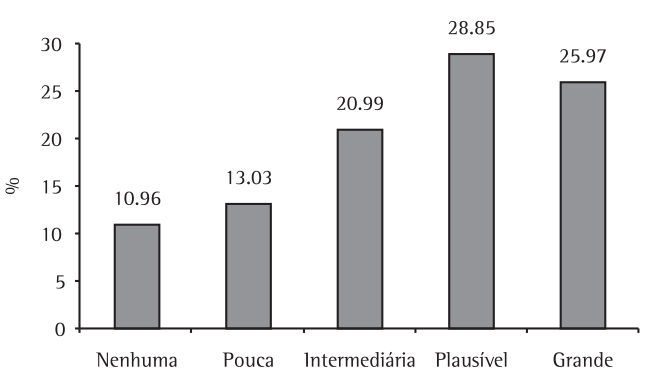

Figura 2. Inovação organizacional: redes de empresas nos APLs de confecção do estado do Paraná. Fonte: Autores.

Tabela 1. Níveis de execução de ações para estratégias gerenciais.

\begin{tabular}{lcccc}
\hline Ações estratégicas & $\begin{array}{c}\text { Formação gerencial e cultura } \\
\text { empresarial (\%) }\end{array}$ & $\begin{array}{c}\text { Formação de parceiros } \\
(\%)\end{array}$ & $\begin{array}{c}\text { Implementação de TICs } \\
(\%)\end{array}$ & $\begin{array}{c}\text { Políticas públicas } \\
(\%)\end{array}$ \\
\hline Nenhum & 0,00 & 2,00 & 28,87 & 13,39 \\
Pequeno & 9,65 & 11,20 & 22,81 & 8,27 \\
Médio & 32,46 & 15,04 & 18,42 & 18,02 \\
Plausível & 39,47 & 33,33 & 15,79 & 27,82 \\
Grande & 18,42 & 39,10 & 14,04 & 32,33 \\
Total & 100 & 100 & 100 & 100 \\
\hline
\end{tabular}

Fonte: Autores. 
produção de produtos personalizados e de alto valor agregado. Assim, encontra-se na indústria de confecção paranaense a necessidade de inovação de produtos e processos voltados para design e altas tecnologias, com ações para a qualidade e sustentabilidade dos produtos e foco nos resultados de coleções anteriores, como mostra a Tabela 3.

As ações de qualidade e sustentabilidade no desenvolvimento de novos produtos e processos pontuaram o maior valor nas opções nenhum ou pequeno nível de execução nos APLs de confecção. Quase 40\% dos envolvidos na pesquisa demonstraram não ter nenhuma ação voltada para a qualidade e sustentabilidade de produtos e processos. Os planos de ação dos APLs apresentam várias atividades que necessitam de apoio de governo, desde a construção de um portal na cidade que identifique a cultura da produção de vestuário, até construir centro de pesquisa para desenvolvimento de novas matérias-primas. Todavia, somente $13 \%$ dos pesquisados indicaram que essas ações foram realizadas no decorrer dos quatro anos de organização em APLs.

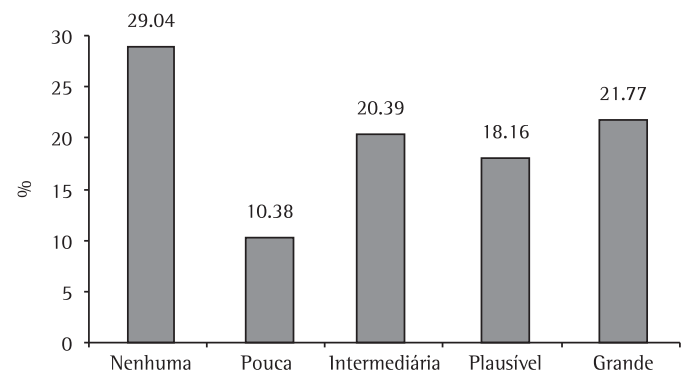

Figura 3. Inovação em marketing: uma imagem de marca forte nos APLs de confecção do estado do Paraná. Fonte: Autores.
A inovação de produtos e processos nos APLs de confecção do estado do Paraná tem suas estratégias e ações voltadas somente para a aquisição de tecnologia de processo. Quando a variável é desenvolvimento de novos produtos, ela se restringe a estudo de novas tendências internacionais por meio de visitas a desfiles e feiras. 0 índice nenhuma ação que envolve inovação de produtos e processos apresenta valor de 34\% e somente $10 \%$ na opção grande frequência, o que apresenta que a cultura dos empresários ainda não é a busca da GDP em conjunto. 0 que foi indicado é que quanto maior a variação de produto no APL, maior a dificuldade de execução de ações nessa área. A parceria das empresas com universidades e institutos de pesquisa para novas tecnologias beneficiaria o APL como um todo, pois a grande dificuldade das indústrias de vestuário consiste na produção de itens diferenciados em quatro coleções anuais, de acordo com a sazonalidade de tempo para cada estação (primavera, verão, outono e inverno).

Duas afirmações constatam a realidade das estratégias de inovação de produtos e processos nos APLs de confecção: "Participar do APL não é ser irmão, pois não vou adquirir uma tecnologia, principalmente de equipamentos, pagar por ela e oferecer de graça o conhecimento para operá-la para os outros integrantes". A figura 4 apresenta os índices de inovação de produtos nos APLs pesquisados. "Não executamos atividades de desenvolvimento de produtos em conjunto, porém após serem lançados e colocados nas vitrines, eles são copiados em questão de dias". Um projeto de desenvolvimento com a teoria open innovation é o Projeto Criando Moda, no qual estudantes universitários de três cursos de moda do estado apresentam coleções em um grande desfile.

Tabela 2. Níveis de execução de ações para estratégias de marketing.

\begin{tabular}{lcccc}
\hline Ações estratégicas & $\begin{array}{c}\text { Gestão da marca em conjunto } \\
\text { do APL (\%) }\end{array}$ & $\begin{array}{c}\text { Mercado nacional e } \\
\text { internacional }(\%)\end{array}$ & $\begin{array}{c}\text { Propriedade industrial } \\
(\%)\end{array}$ & $\begin{array}{c}\text { Cultura Empresarial } \\
(\%)\end{array}$ \\
\hline Nenhum & 14,72 & 34,59 & 50,00 & 15,79 \\
Pequeno & 8,42 & 12,03 & 18,42 & 7,89 \\
Médio & 26,32 & 15,79 & 23,69 & 31,58 \\
Plausível & 22,12 & 15,79 & 2,63 & 34,21 \\
Grande & 28,42 & 21,80 & 5,26 & 10,53 \\
Total & 100 & 100 & 100 & 100 \\
\hline
\end{tabular}

Fonte: Autores.

Tabela 3. Níveis de execução de ações para estratégias de inovação de produtos e processos.

\begin{tabular}{lcccc} 
Ações estratégicas & $\begin{array}{c}\text { Qualidade e sustentabilidade } \\
(\%)\end{array}$ & $\begin{array}{c}\text { Foco no resultado } \\
(\%)\end{array}$ & $\begin{array}{c}\text { Políticas públicas } \\
(\%)\end{array}$ & $\begin{array}{c}\text { P\&D (tecnologia e inovação) } \\
(\%)\end{array}$ \\
\hline Nenhum & 32,40 & 21,05 & 43,16 & 36,84 \\
Pequeno & 21,05 & 6,32 & 9,47 & 11,82 \\
Médio & 24,56 & 25,26 & 11,58 & 19,74 \\
Plausível & 15,31 & 27,37 & 14,74 & 18,42 \\
Grande & 7,43 & 20,00 & 21,05 & 13,16 \\
Total & 100 & 100 & 100 & 100 \\
\hline
\end{tabular}

Fonte: Autores. 
Como consequência, empresários compram modelos e os estudantes são reconhecidos no mercado da moda estadual. Uma parceria universidade-empresas que gera resultados positivos para ambas as partes.

\subsection{Novos materiais utilizados nas matérias-primas de confecção: valor agregado e sustentabilidade}

$\mathrm{Na}$ indústria de confecção, especificamente vestuário e acessórios, a principal matéria-prima é o tecido. Ele determina o nível de flexibilidade, qualidade, conforto térmico, resiliência e maciez da peça do vestuário. Portanto, pensar na GDP em confecção sem parcerias de desenvolvimento com empresas fornecedoras de tecido, analogamente, seria pensar no desenvolvimento de um carro sem manter parcerias com fornecedores de aço ou plástico. Porém, ANPEI (ASSOCIAÇÃO..., 2004) mostra que o setor têxtil que compreende as empresas de fiação e tecelagem e beneficiamento investe $11 \%$ a mais em desenvolvimento de produtos em comparação com as empresas de vestuário e acessórios. Esse fator ocorre porque geralmente empresas de vestuário e acessórios são de médio, pequeno e até micro porte, ao contrário das empresas têxteis, que são de grande porte, realidade a qual é apresentada na Tabela 4.

Com relação aos novos materiais empregados como matéria-prima nos APLs de confecção do estado do Paraná, mais de 75\% dos envolvidos responderam que não têm nenhuma ou poucas ações sobre o tema, conforme ilustrado na Figura 5.

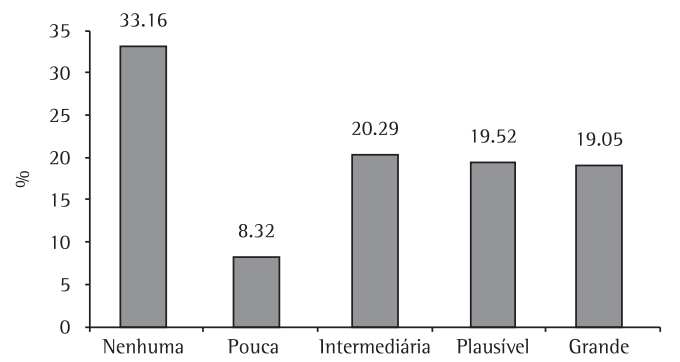

Figura 4. Inovação de produtos e processos: uma imagem de marca forte nos APLs de confecção do estado do Paraná. Fonte: Autores.
Parcerias para ações estratégicas com fornecedores são a maior dificuldade que os APLs de confecção encontram na GDP, com 54\%, aproximadamente, de nenhuma ocorrência e $25 \%$ de pouca ocorrência. Mesmo realizando compras em conjunto ou pelo mesmo representante, as empresas não veem os APLs de confecção do estado do Paraná como um cliente tímido em relação ao volume de compras no mercado. Mas o APL de malhas de tricô de Imbituva tem como seu fornecedor principal a fiação, dessa forma podem-se encontrar parcerias para a criação de produtos ecologicamente corretos. A fiação produz fios com tingimento natural e a confecção efetua sua produção sem degradação do meio ambiente, principalmente sem o processo de estamparia. Com essa sociedade tem-se como estratégia de marketing um produto de vestuário inovador e ecologicamente correto, blusa de tricô com rápida degradação no ambiente.

Os dados conseguidos na pesquisa apresentam a realidade de pouco desenvolvimento de produtos diferenciados dentro dos APLs de confecção do estado do Paraná e, como consequência, a falta de parcerias de desenvolvimento de materiais com fornecedores e acesso a essas novas tecnologias. Uma comparação entre as inovações organizacionais, marketing, produto e processos e novos materiais é apresentada na Figura 6.

A ação inovativa que apresenta o maior índice de práticas nos APLs é a inovação gerencial. Para apoiar este dado, a afirmação de um dos entrevistados: "O conceito de APL veio para organizar o trabalho que já estava sendo feito por agentes externos, que muitas vezes se tornava repetitivo pela falta de comunicação e organização". Assim, essa inovação era um trabalho já realizado anteriormente por instituições de fomento de PMEs e até governamentais, porém não era organizado.

A inovação em marketing em conjunto é apresentada fortemente em algumas regiões, mas se encontra dividida entre as opções nenhum e grande. Este fator é caracterizado pela natureza do produto e o tipo de inventário. Os APLs que trabalham com shoppings atacadistas tendem a ter marketing em conjunto, contrariamente às empresas com representantes que investem em marketing da marca da própria empresa.

Tabela 4. Níveis de execução de ações para novos materiais.

\begin{tabular}{lcccc}
\hline Ações estratégicas & Design estratégico (\%) & P\&D inovação (\%) & Propriedade industrial (\%) & Acesso à tecnologia (\%) \\
\hline Nenhum & 48,54 & 62,52 & 39,26 & 59,78 \\
Pequeno & 24,11 & 13,57 & 37,74 & 22,70 \\
Médio & 15,38 & 13,99 & 17,65 & 13,28 \\
Plausível & 9,61 & 7,89 & 18,00 & 3,09 \\
Grande & 2,11 & 2,63 & 0,00 & 1,25 \\
Total & 100 & 100 & 100 & 100 \\
\hline
\end{tabular}

Fonte: Autores. 
$A$ inovação $P \& D$, mesmo com participação de academias, se resume à compra de máquinas para otimização de novos processos e treinamento de ferramentas gerenciais para melhora do processo produtivo. 0 desenvolvimento dificilmente é realizado em conjunto e a competitividade entre eles só permite a cooperação nas inovações gerenciais, porém o fator crítico encontra-se na inovação, criação de novos materiais, ou seja, na parceria com fornecedores. Nessa inovação não se encontram ações consolidadas em nenhum dos APLs pesquisados, consequência da falta de desenvolvimento do produto em conjunto e até de perceber a sua importância para os produtos manufaturados no arranjo.

\section{Considerações finais}

A gestão dos APLs de confecção do estado do Paraná encontra dificuldades para efetuar ações para as estratégias inovativas planejadas nos planos de ação dos APLs. As inovações de marketing, produtos e processos se consolidam somente em treinamento para colaboradores da empresa e visitas a feiras de produtos e processos do setor. Esse fator ocorre por causa do tempo reduzido de ciclo de produto da confecção e a complexidade para, em conjunto, seguir as tendências de moda e o clima do mercado que se deseja atingir. No entanto, falta confiança aos próprios agentes de governança dos arranjos

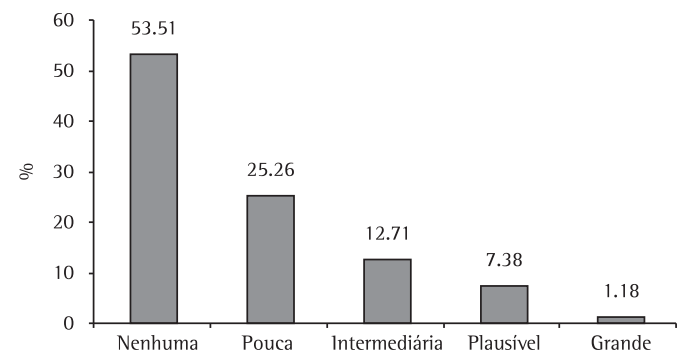

Figura 5. Novos materiais utilizados como matéria-prima de confecção. Fonte: Autores.

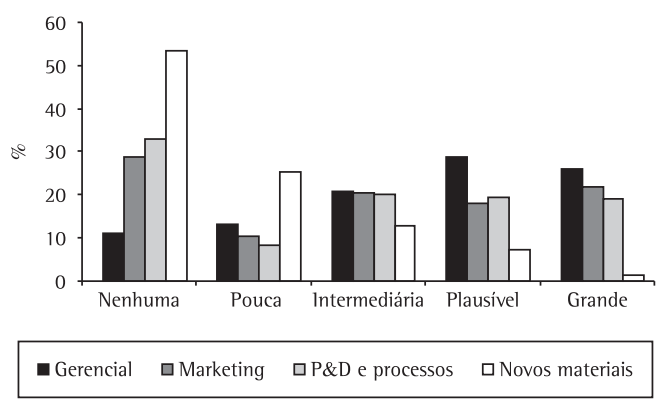

Figura 6. Comparativo entre as inovações do PREPFIP. Fonte: Autores. pesquisados nos benefícios que uma marca em conjunto e o desenvolvimento de produtos podem trazer à região onde o APL está inserido e, como consequência, ao seu reconhecimento no mercado nacional e até internacional.

Os APLs de confecção paranaenses não apresentam ações significativas no desenvolvimento de matériasprimas a partir de parcerias com fornecedores. Há dificuldade de evoluir da fase de organização e formação com novos parceiros para desenvolvimento de produtos em conjunto. Porém, o APL que conseguir superar essa fase terá somente o desafio de manter a inovação contínua e passa a ter vida própria.

Não há como concluir essa pesquisa sem considerar a dificuldade da GDP, sem o auxílio de maior de políticas públicas, nas ações do planejamento estratégico dos APLs de confecção. Três APLs pesquisados apresentam projetos para a criação de laboratórios de pesquisa e desenvolvimento conhecidos mundialmente como agências de desenvolvimento regionais, porém nenhum está concluído ou em processo de licitação.

Para as PMEs evoluírem em novos mercados e se manterem no mercado têxtil local onde atuam, necessitam de estratégias fortes de inovação a partir de fornecedores, empresários, universidades, governo e institutos de pesquisa. Contudo, para isso é imprescindivel enfrentar o desafio de superar rapidamente a cultura do medo de desenvolver produtos em conjunto e efetuar políticas públicas para o apoio do desenvolvimento e tecnologia das PMEs. Como proposta, sugere-se a criação de linhas de crédito específicas para a execução de ações de inovação em empresas participantes dos APLs e o apoio governamental para projetos de pesquisa de universidades que foquem o desenvolvimento de produtos para PMEs organizadas em APL.

\section{Referências}

ASSOCIAÇÃO BRASILEIRA DA INDUSTRIA TÊXTIL - ABIT. Departamento de Economia. Disponível em: <http:// www.abit.org.br>. Acesso em: 20 jun. 2012.

AMATO NETO, J. Gestão de sistemas locais de produção e inovação (Clusters/APLs). São Paulo: Atlas, 2009.

ASSOCIAÇÃO NACIONAL DE PESQUISA, DESENVOLVIMENTO E ENGENHARIA DAS EMPRESAS INOVADORAS - ANPEI. Como alavancar a inovação tecnológica nas empresas. São Paulo: ANPEl, 2004.

CASSIOLATO, J. E.; LASTRES, H. M.; MACIEL, M. L. O foco em arranjos produtivos e inovativos locais de micro e pequenas empresas. In: CASSIOLATO, J. E.; MACIEL, M. L. (Orgs.). Pequena empresa: cooperação e desenvolvimento local. Rio de Janeiro: Relume Dumará, 2003.

CARBONARA, N. Information and communication technology and geographical clusters: opportunities and spread. Technovation, v. 2, n. 5, p. 213-222, 2005. http://dx.doi. org/10.1016/S0166-4972(03)00095-6 
CARPINETTI, L. C.; GALDÁMEZ, E. V.; GEROLAMO, M. C. A measurement system for managing performance of industrial clusters: a conceptual model as research cases. International Journal of Productivity and Performance Management, v. 57, n. 5, p. 405-419, 2008. http:// dx.doi.org/10.1108/17410400810881854

CHENG, L. C. Caracterização da gestão do desenvovimento de produto: delineando o seu contorno e dimensões básicas. In: CONGRESSO BRASILEIRO DE GESTÃO DE DESENVOLVIMENTO DE PRODUTO, 2000, São Carlos. Anais... São Carlos, 2000. 9 p.

CHESBROUGH, H.; CROWTER, A. K. Beyond high tech: early adopters of open innovation in other industries. $R \& D$ Management, v. 36, n. 3, p. 229-236, 2006. http:// dx.doi.org/10.1111/j.1467-9310.2006.00428.x

CLARK, K. B.; WHEELWRIGHT, S. C. Managing new product and process development: text and cases. New York: The Free Press, 1993.

COOPER, R. G. Perspective: The stage-gate idea-to-launch process - update, what's new, and NexGen System. Journal of Product Innovation Management, n. 25, p. 213-232, 2008. http://dx.doi.org/10.1111/j.15405885.2008.00296.x

FLEURY, A.; FlEURY, T. L. Estratégias competitivas e competências essenciais: perspectivas para a internacionalização da indústria no Brasil. Gestão \& Produção, v. 10, n. 2, p.129-144, ago. 2003.

INSTITUTO DE ESTUDOS E MARKETING INDUSTRIAL - IEMI. Relatório setorial da indústria têxtil brasileira 2010. São Paulo: IEMI, 2010. v. 10, 160 p.

HANSEN, M. T.; BIRKINSHAW, J. The innovation value chain. Harvard Business, v. 85, n. 6, p. 121-130, 2007.

LAZOI, M. et al. Collaboration an aerospace SME cluster: innovation and ICT dynamics. International Journal of Innovation and Technology Management, v. 8, n. 3, p. 393-414, 2011. http://dx.doi.org/10.1142/ S0219877011002398

LUPATINI, M. Relatório setorial final - Têxtil-Confecção. FINEP: São Paulo, 2007.

MALERBA, F. Learning by firms and incremental technical change. Economic Journal, v. 1, n. 2, p. 845-859, 1992. http://dx.doi.org/10.2307/2234581

NIU, K. H.; MILES, G.; LEE, C. S. Strategic development of network clusters: a study of high technology regional development and global competitiveness. International Business Journal, v. 18, n. 3, p.176-191, 2008.

OLIVEIRA, M. A.; CÂMARA, M. R.; BAPTISTA, J. R. 0 setor têxtil-confecções do Paraná e seus segmentos regionais especializados: 2002-2004. Revista Economia, v. 33, n. 1, p. 83-115, 2007.

O'DWYER, M.; GILMORE, A.; CARSON, D. Innovative marketing in SMEs. European Journal of Marketing, v. $43, \quad$ n. $1, \quad$ p. $46-61,2009$. http://dx.doi. org/10.1108/03090560910923238

PEREIRA, G. M. et al. Comparando flexibilidade no produto, custos e velocidade de desenvolvimento na indústria da moda chinesa e brasileira. Revista Produção, v. 21, n. 1, p. 27-38, 2011. http://dx.doi.org/10.1590/S010365132011005000012

PEREIRA, J. P. C.; CARVALHO, M. M. Cooperação e localidade: uma análise no contexto do agronegócio de flores. Revista Produção, v. 18, n. 1, p. 195-209, 2008. http:// dx.doi.org/10.1590/S0103-65132008000100015

PHAAL, R.; FARRUKH, C.; PROBERT, D. Developing a technology roadmapping system. In: PORTLAND INTERNATIONAL CONFERENCE ON MANAGEMENT OF ENGINEERING AND TECHNOLOGY, 2005, Portland. Proceedings... Portland, 2005.

$\mathrm{PICH}$, M.; LOCH, C.; MEYER, H. A. On uncertainty, ambiguity and complexity in project management. Management Science, v. 48, p. 1008-1023, 2002. http://dx.doi. org/10.1287/mnsc.48.8.1008.163

PORTER, M. Clusters and the new economy of competition. Harvard Business Review, 1998. p. 77-90. PMid:10187248.

ROZENFELD, H. et al. Gestão de desenvolvimento de produtos. São Paulo: Saraiva, 2006.

SEN, A. The US fashion industry: a supply chain review. International Journal Production Economics, v. 11, n. 4, p. 571-593, 2008. http://dx.doi.org/10.1016/j. ijpe.2007.05.022

SENAl. Departamento regional do Paraná. Rotas Estratégicas para o futuro paranaense: roadmapping de produtos de consumo - 2015. Curitiba: SENAI/PR, 2007.

SCHUMPETER, J. The Theory of Economic Development. Cambridge: Harvard University Press, 1934.

SOUZA, S. D.; ARICA, J. Mudança tecnológica e estratificação competitiva em um arranjo produtivo local do setor ceramista. Revista Produção, v. 16, n. 3, p. 88-99, 2006.

\title{
Innovative strategies in cluster: obliquity for the development of fashion products
}

\begin{abstract}
The strategic management of innovation in the Brazilian clothing market has found certain barriers, especially regarding product development in micro and small enterprises. Local Productive Arrangements (LPAs) have been used by organizations as a strategy to overcome this difficulty. This research presents a multi-case study on five LPAs in the State of Parana with four or more years of existence. The total sample consisted of 20 business agents of governance, including presidents of unions and organized associations responsible for Research and Development $(R \& D)$ projects. The study examined $R \& D$ actions presented in the strategic planning arrangements from the consolidation strategies and the Routes of Strategic Project roadmapping for the future of this sector in the State of Parana. Several difficulties were found in the innovation chain process, especially related to the management of joint product development by contractors and cooperation of suppliers and public policies to encourage R\&D in small and medium-sized enterprises (SMEs).
\end{abstract}

\section{Keywords}

Innovation strategy. Product development management. Confection. Local productive arrangements. 